l'Analyse Spectrale Quantitative par la Flamme 1-Propriétés de la Flamme: Réalisation et Utilisation. 2-Analyse des Émissions dans la Flamme. Par Dr. R. Mavrodineanu et H. Boiteux. (Publication de l'Office de la Recherche Scientifique OutreMer.) Pp. vi $+248+11$ plates. (Paris : Masson et Cie., 1954.) Broché 3,800 franes; Cartonné 4,300 franes.

$\mathrm{N}$ this volume, an excellent account is given of the theoretical and practical aspects of flame photometry. The book is divided into two parts, the first dealing with the general properties of flame sources and a very comprehensive consideration of the factors affecting the design of burners, atomizers and other components in a complete flame photometer. There are chapters on photoelectric and photographic mothods, and also on instruments with dispersing systems and with filters. A short account is given of the interferences between different elements.

It is easy to suggest additional material which might have been included in any book, but perhaps a fuller account could have been given of the large amount of work done in recent years on photoelectric instruments, and reference made to the value of interference filters. The effect on flame temperature of the introduction of different salts also deserves attention, as one cause of interference between one element and another.

The second part of the book is concerned with the theory of the emission spectra of the flame itself and of the elements and compounds giving lines used for analysis. Its value lies in the inclusion within a single volume, not only of the spectral terms and energy-levels of a great many elements, but also of a full account of the molecular spectra of interest and the chemical reactions and equilibria within the flame. A list of useful spectral lines, and photographs of a number of flame spectra are included. There is an extensive bibliography of more than five hundred references, and a good index. The book makes a distinct contribution to a subject which has not recently been presented in a form primarily intended. for the analyst.

J. R. Stansfield

\section{Geology of Petroleum}

By A. I. Levorsen. (A Series of Geology Texts.) Pp. $x+703$. (San Francisco: W. H. Freeman and Company ; London: Bailey Bros. and Swinfen, Ltd., 1954.) 8 dollars ; $68 s$.

GEOLOGIES of petroleum have in the past tended $\checkmark$ to a pattern of theory first, and practice second. In such works the principles are enunciated, explained, diagrammatically presented, and thereafter followed usually with geographically arranged oilfield stratigraphies and structures. Sometimes descriptive matter is too detailed, and a monotonous record of past developments is given; these date quickly unless particularly exemplary. However, the author of this present book is fully aware that there is no point in cataloguing producing pools except as they illustrate specific principles that apply to exploration, for our first interest is in finding now produoing areas, and this point of view is much to be commended.

Unrelieved oil geology, without full leavening of contacts with closely allied sister sciences, lacks inspiration and reality. Recognizing this, the author treats his material objectively : first the reservoir (emphasis on trap rock); then reservoir conditions (temperature, pressure, differential fluids); next "speculative ideas on origin, migration and accumulation" (the operative word here is 'speculative'); and finally, "ways of applying what has been con- sidered in the search for new pools and provinces". There is logic in this sequence. Geological manuscripts are inevitably read in terms of economic values, and theories put to practical trial by drilling. The experienced oil geologist can interpret his findings understandably to geophysicists, reservoir and production engineers and the like; and this applies to administrative 'laymen' as well. Reciprocally, many of these other people desire to learn from a not too technical, modern text something of the geologist's technique. This is the book for them; its appeal should be deservedly wide.

\section{H. B. MILNER}

\section{Entire Functions}

By Ralph Philip Boas, Jr. (Pure and Applied Mathematics: a Series of Monographs and Textbooks.) Pp. xi 276. (New York: Academic Press, Inc. ; London : Academic Books, Ltd., 1954.) 6 dollars. 7 HIS book presents in orderly fashion a wealth of material not previously brought under one cover. It is about functions of exponential type, with emphasis on entire (integral) functions. There are chapters on entire functions of finite order, the minimum modulus and functions with real negative zeros. Then follows a chapter on general properties of functions of exponential type, and then three chapters on special properties, such as the connexion between growth and the distribution of zeros. There is a chapter on uniqueness theorems, and this is followed by a chapter on growth theorems and one on operators and their extremal properties. The last chapter, on applications, is exciting because it demonstrates the wide field within which entire functions find a place. Illustrations are given of applications to Fourier series, power series on the circle of convergence, Dirichlet series and gap theorems. There are brief sections on differential equations of infinite order and approximation. It is a pity that these are so short; but there is an extensive bibliography for those requiring more detail.

A survey of the present book shows that the subject-matter of the theory of entire functions consists of a great number of more-or-less special results. The indications are that these are becoming overwhelming in their numbers and ramifications. One is led to ask the question whether some general theory might be developed which will compress a lot of the known results into several strong channels. It certainly looks as if some new method of classification is needed. It may be that modern algebra and topology can help here, via such tools as ultrafilters and the structure theory of complete local rings, as used recently by Henriksen and others.

L. S. GODDARD

\section{Physics for Medical Students}

By Dr. J. S. Rogers. Third edition, revised and enlarged. Pp. xiii +405. (Melbourne: Melbourne University Press; London: Cambridge University Press, 1953.) 35s. net.

GOR some twenty years Dr. J. S. Rogers's book has done admirable service in providing a course which supplements the ordinary university physics text, with applications of special interest to medical students. In this, the third edition, developments of nuclear physics and electronics are included, together with topics such as reflecting objectives and phase-contrast microscopy. Outstanding in its own field, the book will be gladly welcomed in this new edition.

G. R. NOAKES 